\title{
Left Ventricular Hypertrophy
}

National Cancer Institute

\section{Source}

National Cancer Institute. Left Ventricular Hypertrophy. NCI Thesaurus. Code C50631.

Enlargement or overg rowth of the myocardium of the left ventricle, due to chronic pressure overload. 